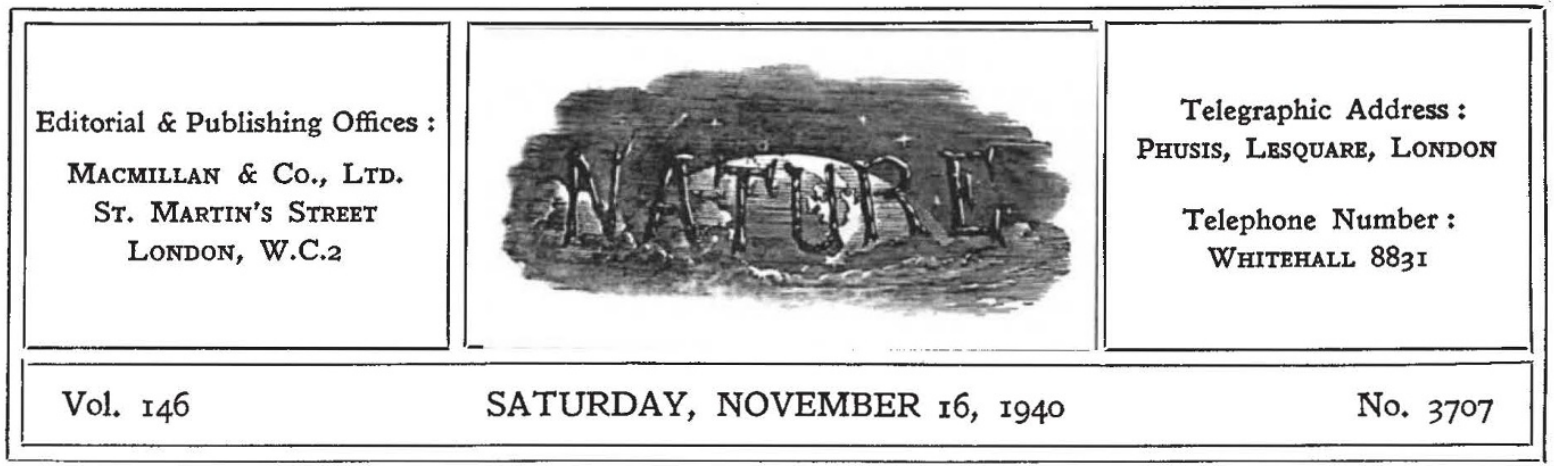

\title{
WELFARE OF YOUTH
}

$\mathrm{O}^{\mathrm{N}}$ $\mathrm{NE}$ of the most remarkable developments that the War has brought has been the concentration of interest on the so-called youth movement. This has been due in large measure to the increasing attention that is being devoted to the question of maintaining good standards of health during the periods of early and late adolescence in order that the valuable work performed by the school medical services might not be undone before maturity is attained. The transitional period marking a young person's introduction to industrial life is properly regarded as being critical from the health point of view, and every attempt at improving those facilities which promote the cultivation of positive attitudes towards health and conduct is bound to receive sympathetic consideration as an effective means in the building of character. Unfortunately, many individuals who bear the responsibility for safeguarding the interests of youth, and particularly some who have voluntarily undertaken work in the various youth organizations, have become extremely suspicious that the attention which is being given to the fourteen to twenty age-group has been artificially engendered with the sole object of providing recruits of a better standard of fitness for the armed forces, and that the continuance of the interest is unlikely to survive when the peace comes (see p. 647 of this issue). This must never be ; the object of any youth movement must be to produce citizens worthy in mind and body of a worthy heritage.

Yet the circulars, "The Service of Youth" and "The Challenge of Youth", issued by the Board of Education during the past year, have, in a few cases, served to strengthen this suspicion because of the emphasis given in them to physical education. Where the circulars have been read in the spirit with which they were written, however, all doubts on this point are readily dispersed. The Board of Education must be credited with having made a genuine attempt to point the way towards the development of a youth movement which should not only become well established during the War, but would also form a highly significant and invaluable means of reconstruction in the peace which is to come.

A more widely held suspicion on the part of youth leaders relates to the steps which the Board of Education has taken in order to encourage interest in questions pertaining to youth. The setting-up of the National Youth Committee soon after the outbreak of War was greeted with acclamation by the many but with very real apprehension by a vociferous minority. The latter regarded this pronouncement as but the first of a series which would lead eventually to what they imagined would be the compulsory regimentation of youth and gradually to the superceding of all voluntary activity and initiative. In no way does one wish to subscribe to this point of view, but it must be said that the situation has been allowed to continue in such an atmosphere of doubt and uncertainty that the National Youth Committee has, by its own unbroken reticence, contributed in great part to the present state of confusion. The position needs immediate clarification if the services of many of the already active youth leaders are to be retained, and if, as is so urgently required, we are to see the extension of the youth programme according to a national policy.

The function of the National Youth Committee appears to have been as carefully concealed as has 
been its constitutional powers and terms of reference. From time to time statements from individual members of the Committee appear in the educational Press but little evidence is forthcoming that the Committee is actively working. The statements themselves are usually of a complacent nature, and express considerable satisfaction at the way the voluntary youth organizations are promoting activities which will guide the young people of the country to fuller and richer lives. One cannot fail to accord a grateful sense of appreciation for the work being carried out by the voluntary organizations; but many of their own workers are seeking both the direction in which the youth policy is to proceed and means to promote the efforts required. This was expressed very clearly recently in a journal devoted to the interests of a boys' movement, when a writer remarked that the only certain fact about our national youth policy was its non-existence. The difficulties confronting those individuals who are only too anxious to undertake service for youth demands confronting with a resolution born of imagination and matter-of-fact realism. In both respects the National Youth Committee could do more to retain and improve the active support of youth workers.

The problem of dispelling doubts about regimentation is one that will demand the use of considerable tact and discretion. In a recent statement in the House of Commons, the President of the Board of Education stated categorically that the last development he wished to see was a centralized movement with rigid uniformity and standardized practice, which placed older boys and girls under the control of some super-functionary in the central Government. Mr. Ramsbottom's disclaimer about militaristic interpretations of the youth scheme was equally strongly worded. It is to be hoped that the action taken, based on these utterances, will serve to dispel the fears of youth workers and to secure their continual and ungrudging support. Probably much of the existing confusion about regimentation lies in the lack of distinction between freedom and discipline. Nevertheless, to establish this distinction to the satisfaction of democrats is not so easy. The main aim should be to fuse the two. Lack of discipline will obviously lead to chaos, and on the other hand absolute freedom is undesirable for it implies freedom of action, expression of opinion, etc., whether right or wrong. Much time is often wasted by the expression of conflicting opinions concerning a problem which to a balanced mind is already settled. There can be few more exasperating than he who claims his freedom to express his opinion merely in order to argue for argument's sake.

The plight of many youths of both sexes who are 'free' to walk aimlessly about or lounge at corners or in queues with no sense of meaning or purpose in life is too well known to need further comment. The most conservative estimates suggest that at least 60 per cent of our young people have no connexion with any single organization, educational, social, or religious. War work has given most of them employment but has not solved their leisure problems and, in some cases, has only intensified them. Their difficulties will not be entirely solved by the extension of the physical fitness scheme on the lines proposed by the Board of Education, nor even by the provision of opportunities for extending their social and cultural interests. Youth needs a sense of significance in life for the individual and the community; suspicions about regimentation need offer no excuse for lack of guidance. The necessity for imaginative planning and disciplinary action is clearly indicated. Already, many youth leaders are advocating compulsory attendance for all young people at some kind of youth organization. At the moment, the execution of such a proposal is probably unwise and equally impracticable; but, as a matter which will inevitably grow in intensity, merits earnest consideration. Its proponents have the fact of compulsory school attendance up to the age of fourteen years to strengthen their case. They are asking, almost with passionate conviction, why, in the most formative years of their lives, when they are acquiring those habits of body, mind and spirit which determine their whole usefulness to themselves and to the community, the majority of our future citizens should be left to the influence, good or bad as it may be, of their surroundings. Whatever the policy adopted it is essential that the spirit of the voluntary organizations with its enthusiasm and informality should be retained and used as the basis for all future developments.

Another matter upon which clearer light might be thrown relates to the activities of local youth committees. Apart from one or two recalcitrant authorities, who may need disciplinary action to call out their initiative in planning for the welfare of the youth of their area, it appears that these committees have now been formed under the ægis of each local education authority. Their con- 
stitutional powers, aims, and methods of working have been left to local incentive. Already there is ample evidence that, owing to the cautious utterances of the Board of Education, a great sprawling organism is being formed, both unwieldy and uncontrolled. In some cases these youth committees have been constituted merely in an advisory capacity to the local education committee and themselves possess no statutory powers. In others, sub-committees of local education committees have been formed with full statutory powers, while in yet others entirely independent committees have been created. Whatever the method of constitution, it would seem essential for smooth and successful working that these committees be given sufficient elasticity to allow them to develop their planned programmes without being held too tightly under the control of the education committee. At least one secretary-organizer to each committee would appear the necessary minimum for administrative supervision, while it should be strongly urged that religious leaders with experience in youth work should be given greater representation than has hitherto been apparent. Discreet guidance, combined with more dynamic leadership from the central government, would do much to unify the existing diversities and would serve to stimulate retrograde or passive committees into action which is so urgently required.

The calling into being of these youth committees appears to have proceeded so smoothly-albeit scarcely rapidly - that the complacent references in the Press appear to be well merited. In practice, many local authorities have travelled no farther on the road towards the service of youth than was evident a year ago. Credit must be freely given to those authorities who for some months have been actually promoting youth work. Their enthusiasm and progress should serve as a salutary reminder to the greater number of youth committees, who, up to the present, have functioned in name only. The proposals outlined by the Board of Education a year ago should have been carried to a riper stage than has been reached to-day.

Co-operative understanding between youth com. mittees and the voluntary organizations should do much to promote the welfare of youth. On their side, the youth committees should play their part in seeing that emphasis must never be placed on the consolidation of youth work but on its extension and development. The challenge to the youth organizations will be in seeing that the quality of local work is such that it cannot fail to stimulate youth committees to increasing and active support. In many areas, prominent educationists have been self-confessedly amazed at the quantity and quality of youth work that has been carried out in their own areas for some years past without their knowledge. With the collaboration of the educationists, far-reaching measures can be taken to secure the extension of instructional, cultural, and social facilities of all kinds. Vigorous co-operation with the youth committees should allow the voluntary organizations to become doubly active in promoting courses for the equipment of potential youth leaders. The youth leaders themselves should be continuously engaged in pursuing enquiries as to the needs, interests, industrial occupations, home and surrounding conditions, as well as the usual leisure activities of youth. (In this connexion the parts played by the public cinemas and radio as educative processes must not be forgotten or minimized.)

The need for the carrying out of scientific surveys-similar to the one in progress in Manchester and Salford at present-is of overwhelming importance. Where these surveys are not being envisaged, however, youth leaders can, by discreet inquiry, secure information that will become of increasing value if carefully collated. When the nature and extent of the youth problem has been established, it is to be desired that an intensive drive should be launched to persuade boys and girls unattached to youth organizations to become active participants in youth centres. This drive may eventually become one of personal recruitment before the adolescent has left school. A considerable augmentation of existing youth services would be needed to cater for this project.

One factor which inevitably must serve to promote greater effort in the youth field would lie in a better appreciation by society at large of the amount of work already achieved by the national voluntary organizations. A deeper realization on the parts of educationists, men of science, and all other members of the community that the work in boys' and girls' clubs, etc., is no mere side-issue carried out by zealous individuals with little else to do, would contribute greatly to the extension of youth welfare. The comprehensive development of the national youth movement will rest upon the rapidity with which its absolute necessity and importance becomes impressed upon the mind of the general public. 